\title{
A JUDICIALIZAÇÃO DA POLÍTICA NO BRASIL: UMA ANÁLISE DAS ADINS NOS GOVERNOS FHC E LULA
}

\section{Gabriella Maria Lima Bezerra ${ }^{1}$}

\begin{abstract}
Resumo:
$\mathrm{O}$ artigo analisa as ações diretas de inconstitucionalidade (ADINs) nos governos FHC e Lula, com o objetivo de revelar o perfil da judicialização da política no âmbito federal brasileiro. Este processo sofre alterações com a mudança de governo ou é um fenômeno relativamente previsível e consolidado na democracia brasileira? Os resultados demonstram que o controle de constitucionalidade no Brasil teve como padrão os requerentes, sendo os partidos políticos e associações de classe os principais judicializadores; foi um pouco mais rigoroso com gestões reformadoras do Estado e se opôs as mudanças na lei que causassem custos concentrados e benefícios dispersos. Há diferenças significativas nos resultados dos dois governos: FHC obteve um número maior de ações e de derrotas, além do tempo de julgamento ter sido menor. Já Lula reduz o número de ações e o número de derrotas. Entretanto, mesmo com diferenças entre os governos, a taxa de fracasso atingiu no máximo $17,5 \%$. O STF é espaço da contestação de grupos oposicionistas, mas como pouca chance de vitória.
\end{abstract}

Palavras-chave: controle de constitucionalidade; judicialização; ADIN; oposição.

\begin{abstract}
Resumen:
En este artículo, la autora analiza las acciones directas de inconstitucionalidad (ADINs) en los gobiernos FHC y Lula, com intento de revelar el perfil de la judicialización en la política federal brasilenã. Este proceso sufre câmbios entre los gobiernos? Es un fenómeno previsible y consolidado en esta democracia? Los resultados demonstran que el control de constitucionalidad tuvo como principales requerentes los partidos políticos y las asociaciones de classe, fue un poco más riguroso con los gobiernos reformadores y opositor de los cambios que promovieran costos concentrados y beneficios dispersos. Por isso, la administración de FHC tuvo un mayor número de derrotas. Sin embargo, mesmo com distinciones entre los dós presidentes, la derrota del gobieno nunca fue mayor que $17,5 \%$ do total de las acciones: Las Adins fueran utilizadas para contestacion de la oposicion, pero sin grandes victorias.
\end{abstract}

Palabras-clave: control de constitucionalidad; judicialización; acción directa de inconstitucionalidad; oposición.

\begin{abstract}
:
The article analyzes the direct actions of unconstitutionality ('ADINs') in the FHC and Lula governments, with the intent to reveal the profile of the judicialization of politics on the Brazilian federal level. Does this process go through changes upon government change or is it a relatively predictable and well-established phenomenon in Brazilian democracy? The results demonstrate that the control of constitutionality in Brazil had as standard the applicants, being the political parties and class associations the main agents of judicialization; it was a little stricter with State's reforming administrations and objected the changes in the law that could cause concentrated costs and dispersed benefits. There are significant differences between the results of the two governments: FHC obtained a greater number of lawsuits and defeats, besides having smaller trial time. On the other hand Lula reduces the number of lawsuits and the number of defeats. However, even with differences between governments the failure rate reached up to $17.5 \%$. The Federal Supreme Court (STF) is the place for the objection of opposition groups, but with little chance of victory.
\end{abstract}

Keywords: control of constitutionality; judicialization; direct action of unconstitutionality; parliamentary opposition.

\footnotetext{
${ }^{1}$ Mestre em Ciência Política pela Universidade Federal do Rio Grande do Sul. Graduada em
} Ciências Sociais pela Universidade Federal do Ceará. 


\section{INTRODUÇÃo}

O processo conhecido por judicialização da política ou politização do judiciário é tema recorrente na literatura. O judiciário integra as análises políticas e é considerado um ator influente das decisões coletivas nas democracias contemporâneas. O desenvolvimento deste processo é característica das democracias consolidadas, de uma maior dispersão das arenas e de um entrelaçamento maior entre os poderes.

O objetivo principal desse conceito é dimensionar o impacto da expansão da atuação do poder judiciário na política. É um fenômeno, portanto, de comportamento institucional. No Brasil, esse movimento se expandiu com o declínio do Estado autoritário e aprovação da "Constituição Cidadã" e com a crise da política macroeconômica da década de 80 .

Neste trabalho, o sentido dado ao termo interessará aqui apenas quando significar disputa legislativa ${ }^{1}$, quando uma instância judicial é chamada a decidir sobre a constitucionalidade de leis e atos normativos ${ }^{2}$. "[...] Poderemos descrever [...] como judicializados os processos políticos nos quais a jurisprudência constitucional tornase paradigma do processo decisório" (TEIXEIRA, 1997, p.20).

Evidentemente esse fenômeno não pode atingir padrões muito diversos - seu escopo é definido por lei. Mesmo dotado de condições restritivas, sua forma é passível de especificidades e merecem investigação, afinal, é uma forma de veto player ${ }^{3}$ ao poder político. O judiciário, portanto, deve ser considerado um importante ator na definição de políticas, já que sua atuação altera o cálculo na definição das mesmas pelos governos.

Além disso, é preciso lembrar que a atuação do judiciário não se faz sozinha, depende que atores se movimentem a protestar por alguma medida: é um fenômeno interligado, dependente do cenário político mais amplo. "Em suma, mesmo uma abordagem institucionalista que considera as estruturas formais no desenrolar do jogo político, deve levar em conta o caráter dinâmico dessas estruturas e sua relação com os desafios ambientais presentes em cada conjuntura” (COUTO, 1998, s.p).

\footnotetext{
${ }^{1}$ Já que o termo pode ser utilizado para diferentes análises sobre as formas de atuação judicial. 2 "Atividade normativa diz respeito a decisões e ações dos órgãos estatais que recebem formulação jurídica. Em geral, essa formulação é necessária para definir com precisão conteúdos e modos de execução daquilo que se vai impor. Atividade normativa se difere de atividade legislativa por englobar diplomas formais com status inferior ao de lei (decretos $e$ portarias do executivo, p.ex.) e superior (emendas constitucionais) [...]" (ARANTES, NUNES, 1998, p.11).

3 "Um veto player é um ator individual ou coletivo cuja concordância é necessária para que se tome uma decisão política [...]”" (TSEBELIS, 1997, s.p).
} 


\section{Entre A Política E JUSTiÇA: Uma ANÁlise da JUdicialização no Brasil CONTEMPORÂNEO.}

Como salienta Carvalho (2005), o controle de constitucionalidade é a arma mais potente do judiciário ao atuar no campo da política, afinal, a capacidade de intervenção do juiz, 'quase' o transforma em ator político, sendo o judiciário elevado a categoria de legislador negativo, causando impactos diretos e indiretos sobre o processo legislativo.

A Assembleia Constituinte optou por se aproximar da revisão constitucional de tipo europeu, ou seja, abstrata com concentração decisional, mas manteve características norte-americanas do controle difuso. Desta mistura, temos um sistema híbrido, em que se desejou assegurar a autonomia do judiciário e a eficácia política, com a eliminação da instabilidade jurídica e das disputas entre instâncias inferiores (ARANTES, NUNES, 1998).

A principal mudança foi a abertura do controle abstrato para mais propositores, que não são exclusivamente parlamentares. Atores sociais e jurídicos foram incorporados, o que significou uma inovação democrática importante para o fomento da cidadania em um momento histórico de afirmação democrática e ampliação de direitos. "O poder Judiciário surge como uma alternativa para a resolução de conflitos coletivos, para a agregação do tecido social e mesmo para adjudicação de cidadania” (WERNECK VIANNA, 1999, p.22). Entendeu-se, portanto, nesse processo, que a democracia representativa não seria capaz de resguardar os direitos individuais e/ou constitucionais.

O controle de constitucionalidade brasileiro é jurisdicional e misto: possui o controle difuso e concentrado, ao mesmo tempo. A ação difusa só acontece quando há um caso de violação constitucional concreto, e a decisão é feita por instância inferior ao STF e é dada somente para o caso. Já o concentrado é julgado unicamente pelo Supremo e requerido através de ADIN - ação direta de inconstitucionalidade, sendo o julgamento uma decisão que contesta a constitucionalidade da lei, sem a necessidade de um caso concreto (ex tunc e erga omnes4).

Segundo o artigo 103 da Constituição Federal, os requerentes legitimados para propor uma ADIN são:

- Presidente da República,

- Mesa do senado federal,

4 Tem efeito retroativo e vale para todos, não só para os solicitaram a ação. 
- Mesa da Câmara dos Deputados,

- Mesa da Assembleia Legislativa,

- Governadores dos estados,

- Procurador geral da República,

- Conselho federal da OAB,

- Partido político com representação no Congresso Nacional,

- Confederação sindical ou entidade de classe de âmbito nacional.

Entretanto, as restrições aos legitimados não foram previamente definidas, salvo os requisitos de admissibilidade e a pertinência temática ${ }^{5}$ que são fruto da jurisprudência construída pelo próprio tribunal ao longo do tempo.

A ADIN pode questionar dispositivos (lei ou ato normativo) estaduais ou federais, neste caso o STF atua como tribunal da federação. Além disso, ADINs podem ser 'por ação' ou 'por omissão', ou seja, pode questionar a inconstitucionalidade de uma lei ou pode exigir a existência de uma lei necessária à concretização da Constituição.

\title{
3. O DISSENSO NORMATIVO NA LITERATURA
}

Anteriormente, a propositura de ação contestadora de constitucionalidade era concentrada nas mãos do Procurador-Geral da República, que se tornou uma antecâmara decisional, ou seja, os interessados na contestação dependiam da decisão daquele ator, dessa maneira, muitos casos nem chegavam ao Tribunal e a julgamento.

\begin{abstract}
A razão política para a ampliação foi, em boa medida, fruto da experiência da subordinação do Procurador-Geral da República aos interesses políticos do Presidente da República. Todas as vezes que partidos políticos ou autoridades procuravam o Procurador com alguma denúncia de inconstitucionalidade e este se recusava a encaminhar a denúncia ao Supremo Tribunal Federal, aumentava o sentimento de consternação e impotência desses segmentos (CARVALHO, 2005, p.146).
\end{abstract}

Mas alguns analistas (por exemplo, Mendes, 1997) ressaltam os efeitos perversos da ampliação de propositura de ADIN, que seria o acúmulo de questões no controle concentrado: o STF atrai praticamente todos os conflitos políticos.

\footnotetext{
5 Os critérios de admissibilidade e pertinência temática são: os legitimados foram divididos em universais e parciais. Os parciais (associações, sindicatos e governadores) precisam ter relação de pertinência com tema do ato questionado (a OAB não foi declarada parcial). Além disso, os sindicatos devem ter associados em pelo menos nove estados - regra análoga à lei orgânica dos partidos políticos.
} 
De maneira geral pode-se dizer que há um dissenso normativo na literatura em torno de dois pólos principais: a) a interferência do judiciário no sistema político protege a minoria de decisões centralizadas, forçando o pluralismo no exercício do poder, significando também o resultado de um amplo processo social de apropriação da cidadania pelos próprios 'cidadãos'; b) a participação do judiciário no policy making significa a interferência nos poderes representativos.

[...] de uma forma geral, é possível dizer que o debate teórico se atém ou termina sendo atraído para um debate das fronteiras entre o direito e a política ou, mais especificamente, para um debate sobre o lugar e a função dos principais atores e instituições políticas no jogo democrático (OLIVEIRA, CARVALHO, 2006).

Para os autores do primeiro grupo (por exemplo, Werneck Vianna e Capelletti) o processo de judicialização é um claro exemplo de que a sociedade está progressivamente buscando seus direitos. Tal postura da sociedade é entendida como uma nova modalidade de se fazer política, e que "teria o condão de obrigar os governantes a observar as aspirações da cidadania expressas diretamente na constituição" (LOBATO, 2001, p.48). Não é possível, portanto, deslegitimar a atuação judicial, afinal esta preenche o vazio da representatividade eleitoral e dá reais possibilidades de acesso ao poder por amplas camadas da sociedade, garantindo a intensidade da democracia autores (WERNECK VIANNA, 1999; CAPELLETTI 1993).

A arena jurídica seria mais um espaço de atuação pública, onde os cidadãos podem se aproximar do poder. Na democracia brasileira ainda há sério descompasso entre a sociedade civil e seus representantes parlamentares. O que estaria a ocorrer é uma procedimentalização do direito - uma apropriação dessa nova esfera para a concretização da vontade coletiva no Estado, rompendo com a burocracia e o ritualismo comum ao espaço público-político (WERNECK VIANNA, 1999). Essa nova forma de democracia é chamada de "soberania complexa" - a articulação de política e justiça. A sociedade civil organizada vê no judiciário uma nova arena para a concretização de seus direitos e interesses. "[...] É importante reconhecer [...] o papel democratizante do Judiciário, agindo tanto como um 'muro de lamentações' quanto como 'uma efetiva arena para o exercício da democracia', em uma democracia na qual a relação entre Executivo e Legislativo foge do ideal" (TAYLOR, 2007, p.249).

Castro (1997) afirma também que a atuação de juízes, advogados e promotores é parte importante no funcionamento democrático e no jogo político. A consolidação constitucional permite uma melhor participação, efetivação democrática, com a inclusão e com a garantia dos direitos individuais. "Em linhas gerais, nossa hipótese é 
que as instituições judiciais brasileiras - especialmente o Judiciário - têm contribuído para o processo recente de liberalização do Estado" (ARANTES, NUNES, 1999, p.31).

O controle judicial sobre os poderes políticos seria importante, além disso, porque ocasiona estabilidade institucional e garante a legitimidade das políticas adotadas, independente do governo em exercício. Afinal, qualquer política para ter vigor precisa estar em consonância não apenas com o interesse momentâneo da maioria, mas seguir um padrão constitucional. A justiça ganha poder decisivo e terminativo nas decisões de políticas públicas, atuando como Corte Suprema, sendo um novo ator no controle e contrapesos das democracias modernas. Oliveira e Carvalho (2006) ressaltam, entretanto, que a interpretação constitucional nunca se igualará ao papel legislador, porque é tecnicamente limitada e porque depende de terceiros - o judiciário não é um ator político ativo.

Para Lobato (2001) isso não significa um 'governo dos juízes', mas apenas faria com que as decisões políticas fossem obtidas com maior dificuldade, fruto do consenso. A efetivação de políticas na democracia não pode ser unilateral, mas deve ser difícil, horizontalizada e verticalizada. E o controle de constitucionalidade é um espaço de controle horizontal do governo em exercício e das maiorias "eventuais". "No Estado democrático a decisão política deve ser o resultado de um amplo debate entre governo e oposição" (LOBATO, 2001, p.48).

A interpretação que privilegia a correlação de forças na arena política entende o processo de outra forma. Os chamados movimentos sociais não têm um grau de articulação parlamentar necessário, não elege uma bancada forte, buscando em outras fontes a realização dos seus interesses. A defesa é, portanto, complicada, porque ao garantir o direito da minoria interrompe outro direito básico que garante a representativa eleitoral da maioria - "a invasão da política pelo direito, mesmo que reclamada em nome da igualdade, levaria à perda da liberdade” (OLIVEIRA, CARVALHO, 2006).

Garapon (1999) vê neste processo de expansão judicial uma crise de legitimidade das democracias representativas e o enfraquecimento do Estado pelo mercado. $\mathrm{O}$ autor ressalta que esse processo não significa apenas transferência de poder, afinal, a possibilidade de atuação do judiciário se dá por processos construídos dentro do legislativo. O que realmente se deu foi uma abundância de legislação na vida do indivíduo, ou seja, há uma transferência da atuação política do legislativo para o judiciário, sem caráter comunitário e sim individual. "Enquanto a democracia reforça a identidade do sujeito individualista a justiça destitui a autoridade tradicional” (OLIVEIRA CARVALHO, 2006). O cidadão individualizado não mais se envolve em 
questões de mobilização social e a justiça se torna um verdadeiro balcão de queixas sociais.

Este modelo, que dá ao judiciário o difícil papel de guardião da constituição, torna as relações entre os poderes nebulosas e conflituosas. E coloca-o em uma situação difícil, ao gerar expectativas de consolidação dos ideais constitucionais, que não dependem apenas da decisão de um juiz, mas de políticas públicas. Essa pressão é indesejável para os governos e incompatível com as definições político-representativas sem contar os malefícios para o sistema econômico, devido à morosidade da justiça e a instabilidade das decisões.

Já para os analistas do sistema político-institucional, é preciso levar em conta a governabilidade e o desempenho dos sistemas políticos. A incorporação do jurídico no jogo político torna a tomada de decisão ainda mais difícil, pois introduz mais um ator na disputa. Nosso sistema é liberalizante ao mesmo tempo em que onera nossa governabilidade, “[...] a dispersão de fontes de poder e as possibilidades institucionais de veto tornam o processo de tomada de decisão política uma via crucis” (ARANTES, NUNES, 1999, p.38).

Portanto, torna-se importante identificar os parâmetros usados pelo STF no julgamento das ações e se são levados em conta na deliberação do executivo e do legislativo, isto é, avaliar em que medida as decisões do supremo direcionam a política e repercutem em orientações para as ações futuras dos poderes. Esse impacto pode ser retrospectivo e direto, porque anula um ato normativo específico e já aprovado, e prospectivo e indireto, ao criar parâmetros decisionais que influenciarão o processo deliberativo do legislador, que deverá levar em conta as definições anteriores do tribunal. "[...] o tribunal constitucional não apenas resolve uma demanda como também elabora a constituição gerando um duplo impacto no processo legislativo" (MAUÉS, FADEL, 2006, p. 9).

\section{ESTUdOS DAS ADINS NO BRASIL}

Teixeira (1997) foi um dos precursores desse tipo de estudo no Brasil. Sua pesquisa revela o perfil de decisão do STF no julgamento das ADINs. "Um dos interesses do estudo nesse campo tem sido o de dimensionar esse papel e o modo pelo qual - e com que grau de previsibilidade e de impacto sobre o processo decisório - o poder judiciário interage com os poderes executivo e legislativo no regime democrático" (idem, p. 16). 
O que se vê é um alargamento das questões levadas ao STF, conseqüência da ampliação do protagonismo do poder judiciário. Além disso, era forte a oposição dos setores nacional-desenvolvimentista aos movimentos reformadores do Estado na recente agenda política brasileira, como eram minorias no campo das grandes decisões, recorreiam quase sempre às ADINs. Ou seja, o ambiente político tem influência sobre as ações, ainda mais se as questões envolvidas forem polêmicas e custosas socialmente. Ir ao STF não significa, entretanto, que os atores estejam dispostos a resolver a situação ou tentar uma nova rodada de decisão, pode significar apenas uma sinalização política, afinal é fácil movimentar uma ação, não há constrangimentos institucionais.

Castro (1997) fez a mesma análise de Teixeira (1997), suas conclusões são próximas: As ADINs analisadas revelam que os tópicos levados ao STF dizem respeito em sua maioria à política fiscal e tributária ou matéria processual, com significativa ausência de decisões sobre direitos fundamentais (não econômicos). Ou seja, “[...] o STF preponderantemente não tem desenvolvido jurisprudência em proteção a direitos individuais e em contraposição às políticas governamentais” (CASTRO, 1997, s.p.).

A dispersão dos atores segundo os tópicos de lei acionados são regidas pela lógica de interesse de cada grupo. Os atores políticos e jurídicos concentram mais de 60\% de suas ações em apenas dois tópicos de lei. Os primeiros concentram-se na administração civil (42,9\%) e na competição política (19,9\%) e os jurídicos dão preferência à administração judicial (54,3\%) e à administração civil (26,4\%). Já os atores sociais, com uma ampla gama de interesses dispersos, não obedecem ao mesmo padrão dos demais atores (CARVALHO, 2005).

De maneira geral, as questões relativas às questões econômicas e a reforma do estado não tiveram nenhuma decisão favorável para os requerentes: o tribunal foi favorável as ações em questões envolvendo administração pública, política tributária, competição política e administração judicial. E não se mostrou favorável à política macroeconômica, privatizações, regulação, meio ambiente, reforma agrária e relações trabalhistas (MARANHÃO, 2003).

\footnotetext{
Possivelmente, num momento de crise econômica e de fortalecimento das instituições políticas democráticas, com presidentes eleitos pelo voto direto dos brasileiros, o tribunal não considerou apropriado alterar ou dificultar a implementação de tais políticas, porque o país necessitava de transformações e, mesmo que particularmente pudessem não concordar com algumas medidas, os ministros não quiseram arcar com decisões contrárias a planos econômicos que poderiam funcionar positivamente (idem, 115).
}

Entretanto, as questões que significaram a imposição de custos concentrados em grupos específicos e sem a devida compensação levaram a decisões favoráveis do 
STF, sagrando-se como instância de veto. "Assim, percebeu-se que alguns assuntos específicos sobre determinados temas da agenda política podem influenciar as decisões dos juízes [...]” (idem, 82)

As pesquisas, em geral, constatam que poucas são as ações que chegam ao julgamento de mérito, a maioria perde seu objeto antes do primeiro julgamento, tantas outras aguardam muito tempo para serem julgadas e quando há julgamento, o que se vê é uma enxurrada de liminares.

Da Ros (2006) investigou o grau de atuação do STF sobre as Medidas Provisórias (MPs). Para o autor existe o interesse sim do tribunal de intervir no jogo político, mas é impedido pelas formatações institucionais - uma MP tem reduzida existência, não são julgadas a tempo, tornam-se ações prejudicadas e seu mérito não pode ser avaliado. Além disso, mesmo quando existe a possibilidade de julgamento, o STF se depara com uma situação parecida com a do Congresso quando a avalia: tem diante de si uma situação distante do status quo, afinal ela já está gerando resultados e ao julgá-la tem que levar em conta as consequências da reversão da medida.

Já Oliveira (2005) analisou o impacto do poder judiciário no Plano de Desestatização das empresas brasileiras, especialmente no governo FHC. A autora trata o fenômeno como um processo. Não basta a tentativa por partes dos partidos, sindicato, governadores, de impedirem a atuação do executivo, é necessário também que a Justiça julgue efetivamente a ação. Ou seja, se houver apenas o acionamento do judiciário por parte desses grupos oposicionistas não é possível falar em judicialização da política, mas em politização da justiça. Para a autora, só se pode falar em judicialização quando o judiciário responde as ações, independente do resultado. E no Brasil esse ciclo não se completa: das 39 ações pesquisadas, apenas uma obteve julgamento de mérito e foi julgada improcedente. "O elevado número de ações pode ser apenas uma expressão do novo formato institucional adotado [...]” (idem).

Em relação aos resultados e ao poder de interferência do judiciário no sistema político, o diagnóstico é o mesmo: o STF julga muito pouco a favor dos requerentes, sendo a taxa de fracasso do governo de no máximo 18\%, com possibilidade de reversão no julgamento final. Teixeira (1997) faz uma analogia interessante. Para o autor, as liminares podem ser vistas como as MPs do STF. As duas são provisórias e fartamente utilizadas. Além disso, ao decidir liminarmente o STF utiliza-se de cautela política, observando os impactos de sua decisão. Mas, pode significar também uma solução plausível diante de uma agenda abarrotada e da cobrança por respostas.

Porque os atores ainda recorrem com tanta freqüência ao judiciário mesmo sendo a possibilidade de vitória tão reduzida, como apresentado? Segundo essa 
literatura, as ADINs servem como uma forma de desmerecer a política em questão e o governo, para 'mostrar serviço' e para retardar ou conturbar o processo decisional, ou seja, o teor das políticas e da oposição ditam o ritmo e a intensidade da judicialização, indicando o grau de polarização política no Brasil.

O uso efetivo das táticas judiciais propiciadas pelo arranjo institucional existente não pode ser entendido, portanto, como uma função mecânica do mero oposicionismo ao governo, mas deve integrar também a saliência dos temas tratados e o próprio ambiente político em que semelhante tática é empregada (TAYLOR; DA ROS, 2008, p.829).

\section{As ADINS NOS Governos FHC E LULA}

O processo de transição brasileiro se completa em 2002 com a ascensão de Lula ao Poder Executivo. A vitória da oposição não deflagrou nenhuma reação objetiva e producente contra o sistema constitucional vigente - diante de tantas quebras e golpes na história democrática brasileira, o fato se anuncia como a consolidação efetiva do processo democrático. Com a ascensão da oposição será que as conclusões clássicas se mantêm? Existe um perfil de judicialização no Brasil independente do grupo político no poder? Afinal, seria o judiciário estratégico para as decisões políticas?

A análise aqui realizada se deu com a coleta de dados no site do STF e com a construção de um banco de dados pessoal. Foram coletadas apenas as ADINs que questionavam dispositivos federais e apresenta resultados das ações julgadas até 28 de agosto de 2011, data do último acesso. Foram contabilizadas 519 ações no período Cardoso e 419 do Lula (Tabela 1), totalizando 938 ações. O governo FHC foi marcado por intensa Reforma do Estado, com sucessivos cortes aos direitos com o objetivo de 'enxugar a máquina' e, por conseguinte, enfrentou um número maior de ações, sem contar a forte e sistemática atuação dos partidos de oposição e das associações de classe.

\section{QUADRO 1}

Número de ADINs por ano nos governos FHC e Lula.

\begin{tabular}{|c|c|c|c|c|c|c|c|c|c|}
\hline Governo & $\mathbf{1}^{\mathbf{0}}$ ano & $2^{\mathbf{0}}$ & $3^{\mathbf{0}}$ & $4^{0}$ & $5^{\mathbf{0}}$ & $6^{0}$ & $7^{0}$ & $8^{0}$ & Total \\
\hline FHC & 58 & 57 & 77 & 82 & 66 & 79 & 59 & 41 & $\mathbf{5 1 9}$ \\
\hline Lula & 28 & 58 & 61 & 34 & 56 & 63 & 71 & 48 & $\mathbf{4 1 9}$ \\
\hline
\end{tabular}

Fonte: STF, 2011. Elaboração Própria. 


\section{1 - Os Dispositivos Questionados}

Em ambos os governos, as ADINs se concentraram no questionamento de medidas provisórias, leis federais e decretos ${ }^{6}$, mas houve variações significativas entre os dois governos. As medidas provisórias assumem o primeiro lugar no governo FHC, com 195 ações, seguidas pelas leis federais com 159. Mas no Lula, são os decretos que assumem o primeiro lugar, com 147 ações, seguidos pelas leis federais (132) e só então MPs (86) (Tabela 2 e 3). No governo FHC, as MPs foram o alvo preferido dos requerentes, assim como os Ministérios (lócus importante da concretização das Reformas do Estado) e o TSE.

Como exemplos, temos a resolução 117, questionada por 17 governadores, pois alterou questões referentes a empréstimos e dívidas com a União. A LC 101 alterou as normas da finança pública, com o intuito de estabelecer responsabilidade na gestão fiscal. A medida provisória 1523 tratava de questões relativas à aposentadoria e benefícios de servidores públicos, por isso o número tão alto de contestações. Já a MP 1415 se referia a previdência social e salário Mínimo e a lei federal 9601 que flexibilizou as relações de trabalho.

\section{QUADRO 2}

Número de Dispositivos questionados por ADINs nos governos FHC e Lula

\begin{tabular}{|c|c|c|}
\hline Dispositivos & Vitória \% & Total \% (N) \\
\hline \multirow{2}{*}{ Decreto } & 20 & $19,3(100)$ \\
\cline { 2 - 3 } & 5,4 & $35(147)$ \\
\hline \multirow{2}{*}{ Lei Federal } & 20,1 & $30,6(159)$ \\
\cline { 2 - 3 } & 9,8 & $31,5(132)$ \\
\hline \multirow{2}{*}{ MP } & 13,8 & $37,5(195)$ \\
\cline { 2 - 3 } & 8,1 & $20,6(86)$ \\
\hline \multirow{2}{*}{ Lei } & 18,5 & $5,2(27)$ \\
\hline \multirow{2}{*}{$\begin{array}{c}\text { Emenda } \\
\text { Constitucional }\end{array}$} & 7,1 & $3,3(14)$ \\
\cline { 2 - 3 } & 16 & $4,9(25)$ \\
\hline \multirow{2}{*}{ Outros } & 24,3 & $8,8(37)$ \\
\cline { 2 - 3 } & 0 & $2,5(13)$ \\
\hline \multirow{2}{*}{} & & $0,7(3)$ \\
\hline
\end{tabular}

${ }^{6}$ Decretos federais podem ser: resolução, parecer técnico, provimento, regimento, portaria, entre outros. 


\begin{tabular}{|l|c|c|}
\hline \multirow{2}{*}{ Total } & 17,5 & $55,3(519)$ \\
\cline { 2 - 3 } & 9,1 & $44,7(419)$ \\
\hline
\end{tabular}

Legenda:

\begin{tabular}{|c|}
\hline FHC \\
\hline LULA \\
\hline
\end{tabular}

Fonte: STF, 2011. Elaboração Própria

Já no Governo Lula, os alvos principais foram o CNJ, recém-criado, os ministérios, o TSE e as emendas constitucionais. Interessante observar que tanto o CNJ e CNMP surgiram depois da Reforma do Judiciário em 2004 e já aparecem judicializados. É significativo o maior número de contestações a emendas constitucionais neste período, mas isso se deve a duas emendas polêmicas: a EC 41, que tratava de questões relativas ao servidor público e a EC 45, que reformou o Judiciário. Como exemplos das leis mais contestadas têm-se: a lei 10826 (desarmamento) e a 11300 que trata do financiamento de campanhas políticas. Já a LC 123 diz respeito ao Estatuto da Microempresa, a MP 131 sobre o comércio e plantio de soja transgênica, a 135 sobre COFINS e a 349 sobre FGTS.

TABELA 1

Dispositivos mais questionados em cada governo.

\begin{tabular}{cccccc}
\hline \multicolumn{6}{c}{$\mathrm{N}^{0}$ do Dispositivo (Número de Processos) } \\
\hline Governo & MP & EC & LF & LC & DEC \\
\hline \multirow{4}{*}{ FHC } & $1523(11)$ & $19(5)$ & $9601(8)$ & $101(7)$ & Senado - Resolução 117 (16) \\
& $1415(10)$ & $21(4)$ & $9100(6)$ & $87(4)$ & Ministérios (13) \\
& $1663(5)$ & $20(4)$ & $9532 / 9096(5)$ & $102 / 105(3)$ & TST (9) \\
& & & & & TSE (7) \\
\hline \multirow{6}{*}{ LULA } & $131(4)$ & $41(15) 45$ & $10826(11)$ & $116(5)$ & CNJ (26) \\
& $135(4)$ & $(13) 52$ & $11300(5) 12034$ & $123(5)$ & TSE (21) \\
& $349(4)$ & $(2)$ & $(4)$ & $128(2)$ & IBAMA (13) \\
& & & & CONAMP/ TST (6)
\end{tabular}

Fonte: STF, 2011. Elaboração Própria.

Poder-se-ia concluir do aumento considerável no número de ações questionadoras de decretos, que o controle de constitucionalidade estaria migrando de decisões políticas centrais - Congresso e Presidência - para as outras instituições. Mas 
essa conclusão é precipitada quando analisamos os casos concretos. Em realidade, o TSE, devido às mudanças nas regras eleitorais em 2006, foi alvo de muitas ações no governo Lula, que provocou esse aumento. As ações desse tipo merecem maior investigação, afinal, elas atingem organismos governamentais muito importantes, como Banco Central, Receita Federal, Tribunais de todos os tipos, Ministérios e Secretarias. E permite que se levante a seguinte hipótese que poderá ser avaliada em futuras pesquisas: será que o executivo, no governo Lula estaria utilizando as secretarias e ministérios para implantar mudanças legislativas, escapando, portanto, das disputas e negociações com o Congresso Nacional? Carvalho destaca, também, o fato de haver "um espaço significativo no embate da regra das regras, devido ao interesse em judicializar as Leis Complementares" (CARVALHO, 2005).

Os dispositivos mais questionados revelam o perfil da gestão, assim como da Oposição nos dois governos. Como afirmam Taylor e Da Ros (2008) “[...] houve uma mudança sensível na pauta de políticas públicas no tocante ao funcionalismo, eliminando-se um dos principais pontos de conflito e de judicialização advinda da esquerda". Houve, no governo Lula aumento relativo do tópico judiciário, diminuição do tópico servidor público, aumento relativo do tópico eleições e agricultura.

\section{2- Os 'Judicializadores'}

A judicialização é aberta a atores sociais, jurídicos e políticos. As Associações de Classe (Tabela 4 e Gráfico 1) e os Partidos (em grande maioria de oposição) são os maiores judicializadores, representam 73,4\% das ADINs no FHC e 69,7\% no Lula7.

\section{QUADRO 3}

Requerentes das ADINs nos Governos FHC e Lula

\begin{tabular}{|c|c|c|}
\hline Requerente & Vitória \% & Total \% (N) \\
\hline \multirow{2}{*}{ Partidos } & 16,3 & $43,8(227)$ \\
\cline { 2 - 3 } & 9,5 & $30(126)$ \\
\hline \multirow{2}{*}{ Associação } & 14,5 & $37,2(193)$ \\
\cline { 2 - 3 } & 5,9 & $44,8(188)$ \\
\hline \multirow{2}{*}{ OAB } & 30,3 & $6,3(33)$ \\
\cline { 2 - 3 } & 18,7 & $3,8(16)$ \\
\hline
\end{tabular}

7 É interessante notar o crescimento no número de ações do Procurador-Geral, mas ainda assim não atinge $10 \%$ do total de ações. 


\begin{tabular}{|c|c|c|}
\hline \multirow{2}{*}{ Procurador } & 55 & $3,9(20)$ \\
\cline { 2 - 3 } & 22 & $9,7(41)$ \\
\hline \multirow{2}{*}{ Governador } & 14,7 & $6,5(34)$ \\
\cline { 2 - 3 } & 20 & $3,9(15)$ \\
\hline \multirow{2}{*}{ Total } & 0 & $2,3(12)$ \\
\cline { 2 - 3 } & 0 & $7,9(33)$ \\
\cline { 2 - 3 } & 17,5 & $55,3(519)$ \\
\hline
\end{tabular}

Legenda:

\begin{tabular}{|c|}
\hline FHC \\
\hline LULA \\
\hline
\end{tabular}

Fonte: STF, 2011. Elaboração Própria.

No governo FHC, as associações mais ativas no controle de constitucionalidade foram:

- Confederação Nacional da Indústria (21 ações),

- CNC - Confederação do Comércio (14),

- CNPL - Confederação Nacional das Profissões Liberais (13),

- CNTM - Confederação Nacional dos Trabalhadores Metalúrgicos (7),

- CONFENEN - Confederação Nacional dos Estabelecimentos de Ensino (7),

- CNTC - Confederação Nacional dos Trabalhadores no Comércio(7),

- CSPB - Confederação dos Servidores Públicos do Brasil (7),

- ADEPOL - Associação dos Delegados de Polícia do Brasil (6),

- ANOREG - Associação dos Notários e Registradores do Brasil (6),

- CNS - Confederação Nacional de Saúde (6),

- CNTI - Confederação Nacional dos Trabalhadores na Indústria (6).

E no governo Lula:

- $\mathrm{CNC}(12)$

- AMB - Associação dos Magistrados do Brasil (12),

- ANAMAES - Associação Nacional dos Magistrados Estaduais (11),

- CONAMP - Associação Nacional dos Membros do Ministério Público (8),

- CONTEC - Conf. Nacional dos Trabalhadores nas Empresas de Crédito (8)

- $\operatorname{ADEPOL}(7)$

- ANAMATRA - Assoc. Nacional dos Magistrados da Justiça do Trabalho (7). 
O PT foi, dentre os partidos, o principal responsável pelas ações no governo FHC (Gráfico 2), atuou em 34\% das ações desse grupo - 69 ações individualmente, mas ainda participou em muitas outras, coligado com os demais partidos de oposição (PC do B, PDT, PSB e PV) - as coligações representaram 32\% (66 ações). O PDT ficou em segunda posição nos dois governos, sendo possível atribuir-lhe o papel de oposição 'convicta', responsável por 18 ações no FHC e 11 no Lula. Já no Governo Lula, PSDB e PFL/DEM (Gráfico 3), juntos somaram 66 ações, 58\% desse grupo, mas participaram em outras 10 ações coligados, às vezes com a ajuda do PPS. Portanto, há forte continuidade na atuação da oposição - pelo menos no que diz respeito ao controle de constitucionalidade (uso de ADINs).

\section{GRÁFICO 1}

Número de ações por partido político no governo FHC

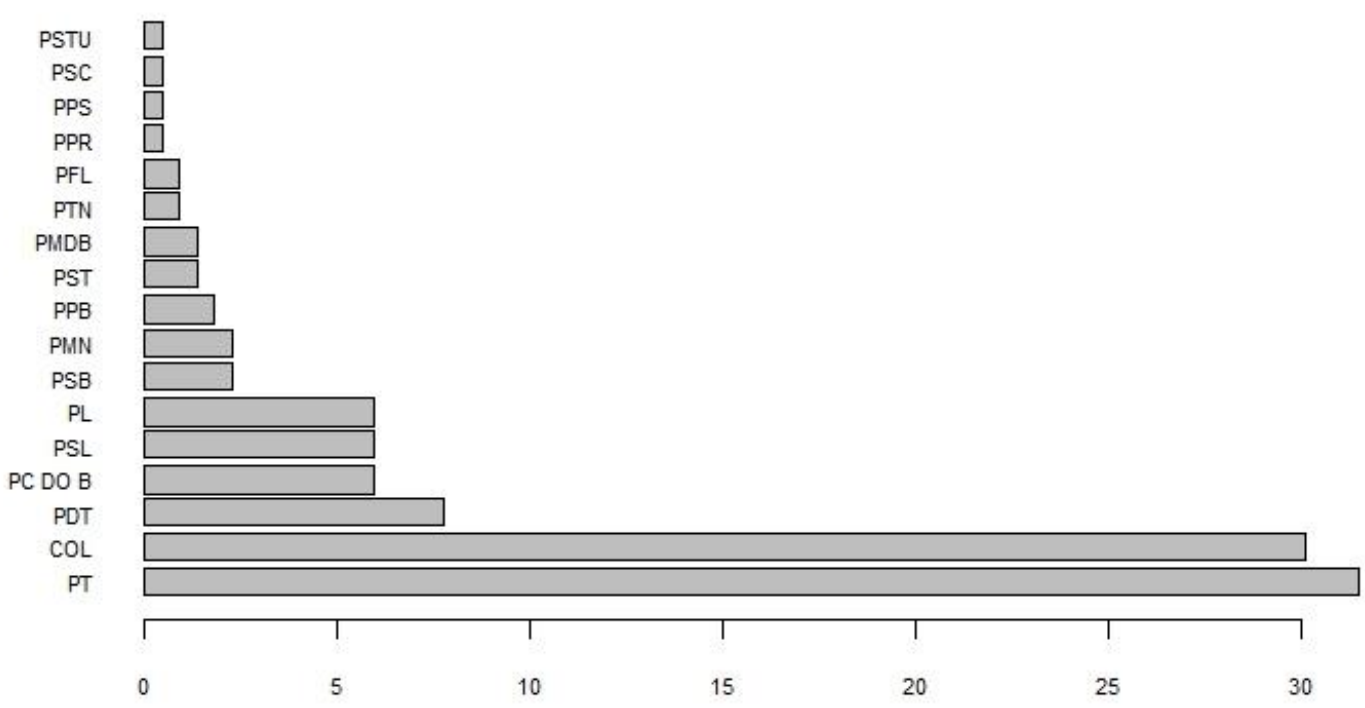

Fonte: STF, 2011.

Elaboração Própria 


\section{GRÁFICO 2}

Número de ações por partido político no governo Lula

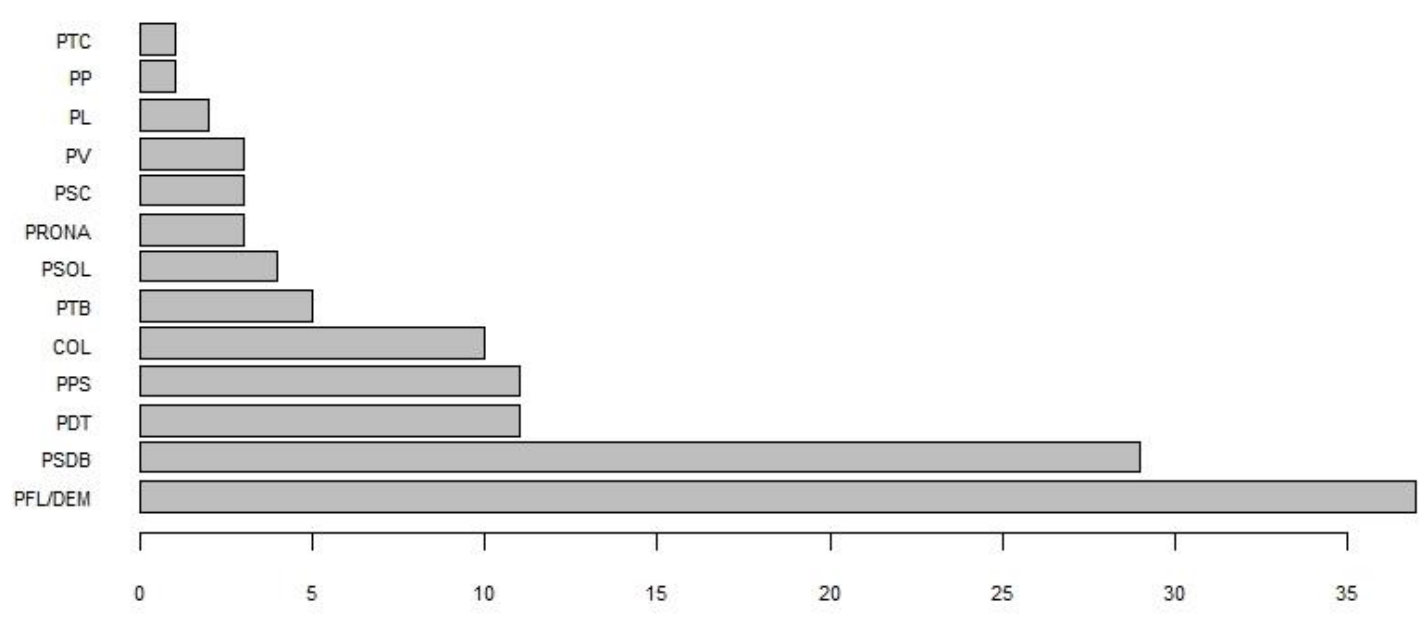

Fonte: STF, 2011.

Elaboração Própria.

\section{3- Tempo de Julgamento}

O tempo de julgamento das ações foi calculado baseado no dia da entrada da ação no STF e o dia do primeiro julgamento, não importando se esse julgamento foi provisório ou final ${ }^{8}$. É importante analisá-lo porque o status quo, ou seja, a demora no julgamento da ação é favorável ao governo.

No FHC (Gráfico 4 e Tabela 5) ${ }^{9}$ esse tempo foi em média maior, e há uma quantidade maior de comportamentos atípicos (tempo de julgamento muito distante da média) do que no Lula. Além disso, FHC possui um número menor de ações não julgadas do que Lula, mas isso se deve a distância da análise que para Lula é menor. É preciso salientar também, aprovação da lei 9868 em 1998, que provocou alterações no julgamento das ADINs. A concessão de liminares, a partir de então, só se daria com a aprovação da maioria absoluta dos ministros do Supremo, dessa forma, tornou-se um

${ }^{8}$ Foram excluídas algumas ADINs da análise por falta de informações no site do STF (último acesso em agosto de 2011).

9 A base da caixa do diagrama representa o primeiro quartil, Q1, a linha central (preta) representa a mediana, Q2, e o topo da caixa, o terceiro quartil, Q3. A distância entre Q3 e Q1 é o intervalo interquartil, IIQ. O limite inferior do diagrama, Li, invisível no gráfico, pois o valor está em dias, ou seja, é impossível que haja um número menor que zero, é calculado como Q1 (1,5.IIQ) e o limite superior, Ls = Q3 + (1,5.IIQ). Os valores que estiverem abaixo do limite inferior ou acima do limite superior são considerados atípicos. 
pouco mais custosa, aumentando o tempo para o julgamento, inviabilizando uma grande parcela das ações por perda de objeto (TAYLOR; DA ROS, 2008).

\section{TABELA 2}

Tempo de Julgamento das ADINs

\begin{tabular}{l|c|c|c|c|c|c|c}
\hline Governo & $\begin{array}{c}\text { Valor } \\
\text { Mínimo }\end{array}$ & $1^{\circ}$ Quartil & Mediana & Média & $3^{\text {o }}$ Quartil & $\begin{array}{c}\text { Valor } \\
\text { Máximo }\end{array}$ & $\begin{array}{c}\text { Aguardando } \\
\text { Julgamento }\end{array}$ \\
\hline FHC & o dias & 14 dias & 76 dias & 426 dias & 259 dias & 4.767 dias & 123 ADINs \\
\hline LULA & o dias & 8 dias & 79 dias & 283 dias & 323dias & 2.639 dias & 220 ADINs \\
\hline
\end{tabular}

Fonte: STF, 2011. Elaboração Própria.

\section{GRÁFICO 3}

Box Plot da Dispersão do Tempo de Julgamento das Adins

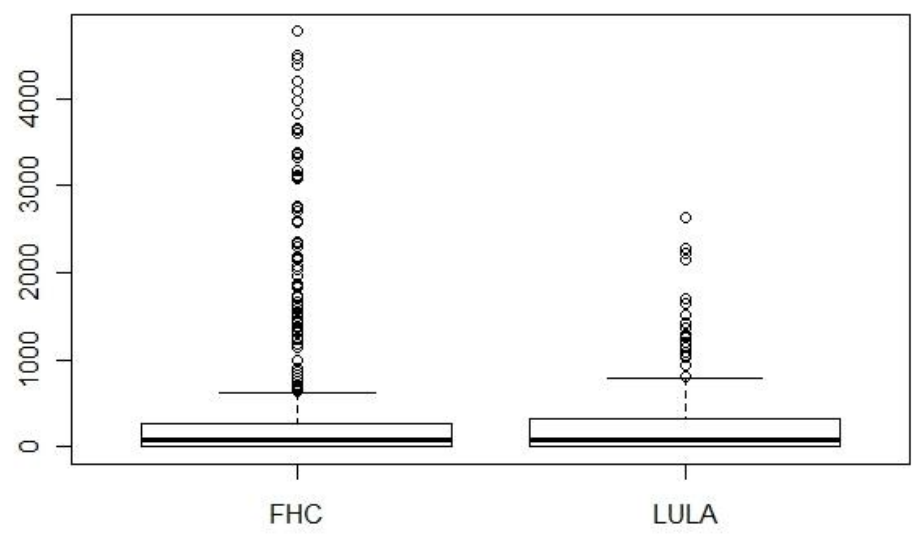

Fonte: STF, 2011. Elaboração Própria.

\section{4- Resultado das Ações}

Nesta análise, os resultados das ações foram considerados "sucesso" quando julgados:

- procedente,

- procedente em parte,

- liminar deferida ou

- liminar deferida em parte; 
E consideradas "fracasso" quando o julgamento favorece o governo:

- liminar indeferida,

- liminar prejudicada,

- não conhecida,

- aguardando julgamento e

- improcedente.

O STF conta com recursos processuais que lhe permite controlar o timing de uma ação e lhe dá a possibilidade de acelerar ou retardar a implementação de uma política, com o uso das liminares ou com o pedido de vistas. Um percentual alto de ações, em torno de 50\%, é julgado duas vezes, a primeira como liminar ou medida cautelar e a segunda vez de forma definitiva (julgamento final). O primeiro julgamento, em muitos casos, se estende no tempo, dificultando uma análise quantitativa dos julgamentos finais. "Ao decidir liminarmente o Supremo poderá rever a sua decisão a partir da análise do impacto causado e das reações a ela do poder ou dos poderes afetados” (TEIXEIRA, 1997, p.113). Por isso analisaremos também o primeiro julgamento, que mesmo podendo ser revertido ${ }^{10}$, causa transtornos ao governo e é sinal de veto:

[...] caso o vencedor da liminar seja o requerente, possibilita cessar a vigência da lei até o julgamento do mérito. Apesar de ser um resultado provisório, surte efeito prático imediato em cada caso específico, sem com isso tornar inconstitucional o dispositivo (MARANHÃO, 2003).

De maneira geral, o Governo FHC se deparou com 17,5\% do total de ações julgadas em favor dos requerentes (Gráfico 6), 91 ações, sendo 37 dos partidos:

- PT com 8,

- $\quad \mathrm{PC}$ do B (2),

- $\operatorname{PDT}(4)$,

- PL (3),

- PSL (2)

$10 \mathrm{O}$ que aconteceu em 40 ações no governo $\mathrm{FHC}$ ( 3 ações julgadas fracasso no primeiro julgamento foram consideradas sucesso no julgamento final, e 37 o oposto). No governo Lula 10 ações julgadas sucesso no primeiro julgamento foram revertidas no julgamento final. É preciso esclarecer que na maioria dos casos, o sucesso de uma ação desaparece por perda de objeto, ou seja, a lei deixou de existir ou foi modificada e não propriamente uma mudança na sentença proferida anteriormente. 
- $\quad$ PSB, PTB, PSC (1)

- Coligações (15), geralmente PT, PSB, PDT, PC do B, e às vezes, o PV.

As associações de classe foram vitoriosas em 28 ações:

- CNI 10,

- $\mathrm{CNS}$ e CNTC (3),

- ANAJUCLA, CONFENEN, Coligadas e CONAMP com (2),

- ANAPE, CNPL, CNTI e ATRICON (1).

Quando se analisa os resultados dos dispositivos questionados, verifica-se que as ações relativas aos decretos e leis federais no FHC têm uma taxa de sucesso elevada em relação aos outros dispositivos, 20\% foram julgadas favoráveis (Tabela 2). Já no governo Lula, as emendas complementares foram responsáveis pelas taxas mais elevadas de sucesso, 24,3 \%. As medidas provisórias ficam abaixo da média nos dois, comprovando a tese de que a demora no julgamento das ações dificulta singularmente a análise de mérito desses dispositivos.

Os resultados das ações por requerentes (tabela 4) mostram discrepâncias que merecem destaque. No governo FHC, o Procurador possui taxa de vitoriosa discrepante em relação à média, com 55\%, 11 julgadas favoráveis, assim como a OAB, 30 (10 ações). No Lula essa discrepância diminui, mas ainda é acentuada, 22\%, 9 ações favoráveis para Procuradores, seguido por Governadores com 20\% (3) e OAB com 18,7\% (3). O que explicaria essa preponderância desses dois requerentes? Na verdade, o grau de contestação desses atores é pequeno em relação aos outros, ou seja, esses atores utilizam as ADINs em casos isolados. Sua bagagem jurídica também tem importância, assim como o tipo de leis que contestam. Como aponta a literatura, o STF não se exime de julgar e discordar em questões de matéria processual e jurídica. Portanto, “[...] a tese de que o Supremo Tribunal Federal, com base na revisão abstrata da legislação vinha assumindo papéis importantes no processo decisório, fica seriamente comprometida. Os dados demonstram que o único papel que a Corte Suprema indica almejar é o de dar a última palavra em assuntos judiciais” (CARVALHO 2005, 148).

O Governo Lula reduz o número de ações (100 a menos), assim como as derrotas em 8,4\%. A taxa de fracasso foi de 9,1\%, 38 ações. Dessas, 11 foram de associações de classe e 12 de partidos: PSDB com 3, PFL/DEM com 2, Coligados, PTB, PPS, PSC, PTC, PT e PDT com uma cada. As associações foram AJUFE e CONAMP com duas ações cada, AMB, ANOREG, ANPR, ABERT, ABRE, CNT E CNTV com uma cada. 


\section{ConClusões}

Não basta para a existência da judicialização, a consolidação da democracia e a tripartição do poder. A justiça por si só é passiva, depende da movimentação de grupos de interesses e que juízes se considerem atores necessários à política.

O controle de constitucionalidade no Brasil teve neste período o domínio de solicitações de ADINs pelos partidos políticos e associações de classe, sendo estes, portanto, os principais judicializadores, ou seja, as oposições diversificaram as arenas de atuação; foi um pouco mais rigoroso com gestões reformadoras do Estado; se opôs as mudanças na lei que causassem custos concentrados e benefícios dispersos e é marcado pelo julgamento de liminares, afinal, o STF utiliza-se de recursos procedimentais que dão andamentos diferentes, sendo comum a perda de objeto antes do julgamento parcial e principalmente antes do julgamento final.

Mas há diferenças significativas entre os dois governos: FHC obteve um número maior de ações e de derrotas. Já Lula não teve o ímpeto reformista como seu antecessor, não afetou tantos interesses e lida com um bloco heterogêneo que minimiza as oposições extremadas, reduzindo o número de ações e o número de derrotas.

Além disso, as vitórias não foram igualmente distribuídas entre os requerentes. O Procurador-Geral e a OAB reduziram seu percentual, mas ainda assim suas ações possuem maior probabilidade de vitória, assim como as associações de classe dos magistrados. Ou seja, ações relativas a questões jurídicas são as que mais causam decisões favoráveis do STF, comprovando a tese de Teixeira, "[...]a judicialização na democracia brasileira é também provocada pela conjunturalização da produção normativa" e se "[...] evidencia de maneira relevante como instrumento de ação das minorias no ambiente de reformas das estruturas básicas do Estado" (TEIXEIRA, 1997).

Mesmo com diferenças entre os governos, a taxa de fracasso atingiu no máximo 17,5\%. Portanto, o STF é espaço da oposição, mas na maioria das ações, o governo ganha: "Nessa arena predominam estratégicas de utilização de alarmes de incêndio e repercussão midíática” (MELO, 2007, p.260).

\section{REFERÊNCIAS BIBLIOGRÁFICAS}

ABRANCHES, S. 1988. Presidencialismo de coalizão: o dilema institucional brasileiro. Dados, 31: 1. 
ARANTES, R.; COUTO, C. 2006. Constituição, Governo e Democracia no Brasil. Revista Brasileira de Ciências Sociais, v. 21, n. 61.

; NUNES, J. 1999. Judiciário e Democracia no Brasil. Novos Estudos, n. 54.

; NUNES, J. 1998. Instituições judiciais e democracia no Brasil. Encontro Anula da Anpocs, 22., Caxambu, out.

CAPPELLETTI, M.1993. Juízes legisladores? Porto Alegre: S. A. Fabris.

CARVALHO, E. 2004. Em busca da judicialização da política no Brasil: apontamentos para uma nova abordagem. Revista de Sociologia e Política, Curitiba, n. 23.

2005. Revisão Abstrata da Legislação e a Judicialização da Política no Brasil. São Paulo Tese de Doutorado em Ciência Política, Universidade de São Paulo. 2007. Revisão Judicial e Judicialização da Política no Direito Ocidental: aspectos relevantes de sua gênese e desenvolvimento. Revista de Sociologia e Política, Curitiba, n. 28.

CASTRO, M. 1997. O Supremo Tribunal Federal e a judicialização da política. Revista Brasileira de Ciências Sociais, São Paulo, v. 12, n. 34. Disponível em <http://www.anpocs.org.br/portal/publicacoes/rbcs $00 \quad 34 / \operatorname{rbcs} 34$ 09 $>$

COUTO, C. 1998. A Longa Constituinte: Reforma do Estado e Fluidez Institucional no Brasil. Dados, Rio de Janeiro, v. 41, n. 1. Disponível em <http://www.scielo.br/scielo.php?script=sci_arttext\&pid=Soo11$52581998000100002 \& \operatorname{lng}=$ pt\&nrm $=$ iso $>$. . 2001. O Avesso do Avesso - Conjuntura e Estrutura na Recente Agenda Política Brasileira. São Paulo em Perspectiva, v. 15, n. 4. . 2005. Constituição, competição e políticas públicas. Lua Nova - Revista de Cultura e Política. N. 65, p. 95-135, maio-ago. 
; ABRUCIO, F. 2003. O segundo governo FHC: coalizões, agendas e instituições. Tempo Social, São Paulo, USP, v.15, n.2.

DA ROS, L. 2006. Supremo Tribunal Federal como veto player? Judicialização da política e restrições à edição de medidas provisórias no Brasil pós-1988. In: XIV Jornadas de Jovens Investigadores da Associação de Universidades Grupo Montevideo, Campinas. Anais da XIV Jornadas de Jovens Investigadores da AUGM.

FIGUEIREDO, A.; LIMONGI, F. 1999. Executivo e Legislativo na nova ordem constitucional. Rio de Janeiro: FGV, 1999.

2007. Instituições políticas e Governabilidade. In: MELO, Carlos Ranulfo; SAÉZ, Manuel Alcântara (orgs.) A Democracia Brasileira. Balanço e perspectivas para o século 21. Belo Horizonte: Editora UFMG.

GARAPON, A. 1999. O juiz e a democracia: o guardião de promessas. Rio de Janeiro: Revan.

LOBATO, A. 2001. Política, constituição e justiça: os desafios para a consolidação das instituições democráticas. Revista de Sociologia e Política, n. 17, p. 45-52.

MACIEL, D.; KOERNER, A. 2002. Sentidos da judicialização da política: duas análises. Lua Nova: Revista de Cultura e Política, São Paulo, n. 57.

MARANHÃO, T. 2003. Quando o Supremo Tribunal Federal Discorda do Presidente da República (1988-2001). Brasília. Dissertação de mestrado em Ciência Política. Universidade de Brasília.

MAUÉS, A.; FADEL, A. 2006. Circuitos interrompidos: as ADINS dos partidos políticos no STF (1999-2004). Disponível em

$<$ http://www.conpedi.org/manaus/arquivos/anais/manaus/direito_e_politica_antoni o_m_maues_e_alexandre_fadel.pdf >

MELO, M. 2007. Hiperconstitucionalização e Qualidade da Democracia. Mito e Realidade. In: MELO, Carlos Ranulfo; SAÉZ, Manuel Alcântara (orgs.) A Democracia Brasileira. Balanço e perspectivas para o século 21. Belo Horizonte: Editora UFMG. 
. 1997. O Jogo das regras: a política da Reforma Constitucional, 1993-1996.

Revista Brasileira de Ciências Sociais, a. 12, n. 35.

MENDES. G. 1997. O poder Executivo e o poder Legislativo no controle de constitucionalidade. Revista de Informação Legislativa, a. 34, n. 134.

OLIVEIRA, V. 2005. Judiciário e privatizações no Brasil: existe uma judicialização da política? Dados, Rio de Janeiro, v. 48, n. 3.

; CARVALHO, E. 2006. Judicialização da Política: um tema em aberto.

Revista Política Hoje, v. 1, n. 15.

SANTOS, F. 2003. O Poder Legislativo no Presidencialismo de Coalizão. Belo Horizonte: UFMG; Rio de Janeiro: IUPERJ.

TAYLOR, M. 2007. O judiciário e as políticas públicas no Brasil. Dados, Rio de Janeiro, v. 5O, n. 2.

; DA ROS, L. 2008. Os partidos dentro e fora do Poder: a judicialização como resultado contingente da estratégia política. Dados, Rio de Janeiro, v. 51, n. 4.

TATE, N.; VALLINDER, T. (org.). 1995. The Global Expansion of Judicial Power. New York: NYU Press.

TEIXEIRA, A. 1997. A judicialização da política no Brasil (1990-1996). Brasília, Dissertação de Mestrado, UnB.

TSEBELIS, G. 1997. Processos decisórios em sistemas políticos: veto players no presidencialismo, parlamentarismo, multicameralismo e pluripartidarismo. Revista Brasileira de Ciências Sociais, v. 12, n. 34. Disponível em < http://www.anpocs.org.br/portal/publicacoes/rbcs oo $34 / \mathrm{rbcs} 34$ 06.htm >.

WERNECK VIANNA, L. 1996. Poder Judiciário, “positivação” do direito natural e política. Estudos Históricos, v. 9, n. 18.

et alli. 1999. A judicialização da política e das relações sociais no Brasil. Rio de Janeiro: Revan. 

Editora UFMG.

(org.). 2002. A democracia e os três poderes no Brasil. Belo Horizonte: ; BURGOS, M; SALLES, P. 2007. Dezessete anos de judicialização da política. Tempo Social, v. 19, n. 2. 